\title{
A methodology for civil engineering technology senior capstone projects with public, private, and federal agency collaboration to assist underserved com- munities
}

\section{Dr. Bryan Knakiewicz, Savannah State University}

Dr. Knakiewicz has seven years of field experience as an Interior Systems Estimator, Construction Crew Supervisor, Municipal Engineer/Inspector, and small business owner. As an Engineer and Inspector for the Village of Dundee, MI from 2006-2010, he managed projects relating to the design, construction, and reconstruction of subdivisions, roadways, public utilities, and site plans, including the Village of Dundee Riverwalk project and The Inflow and Infiltration Control for Wastewater Treatment project. He taught in the Engineering Technology Department at The University of Toledo from 2010-2012 and has been a faculty member of the Engineering Technology Department at SSU since 2012, teaching Highway and Transportation Engineering, Structural Analysis, Steel and Reinforced Concrete Design, Soil Mechanics and Foundations, Civil Engineering Computing Practices, Computer Graphics, Surveying, Construction Management and Scheduling, and Technical Writing. At Savannah State University (SSU), he founded and advises the SSU Engineers Without Borders Student Chapter, and is an advisor for the ASCE-SSU Student Chapter. He is a currently an active member in the ASCE, ASEE, and EWB, with previous and current research projects that include porous asphalt pavement design, the strength of metals, and material testing/finite element analysis. 


\title{
A methodology for civil engineering technology senior capstone projects with public, private, and federal agency collaboration to assist underserved communities
}

\begin{abstract}
A collaboration between undergraduate civil engineering technology students, the United States Environmental Protection Agency's (EPA) College/Underserved Community Partnership Program (CUPP), and the Thriving Earth Exchange (TEX), resulted in a senior capstone project that provided significant benefits to a municipality in rural Georgia facing economic hardship and a need to design a replacement for their insufficient municipal office building. As a result of the students' efforts and the advisement provided by the TEX professional mentor and university faculty advisor, the students gained practical experience through the application of their engineering knowledge and skills into their real-world design. Specifically, their practical experience emanated from data collection, site visits, research of agency standards, sustainable site design and building materials, and in-person meetings and design charrettes between the students, municipal administrators, industry and university advisors, and residents of the community. The logistics of the project development and execution process was unique among typical engineering technology senior capstone projects, as it involved multiple parties to define details such as the scope of the project, the responsibilities of the mentor and faculty advisor, the communication loop between the students, client, and advisors, project scheduling and milestone dates, deliverables, etc. The outcomes of the student project include the development and design of a preliminary site plan and detailed building plans for the proposed municipal office with accompanying economic and environmental analyses. These outcomes were completed with such a high level of quality and rigor that a pro bono engineering firm stamped the engineering plans after minor revisions, and their project was highlighted as the premier student project at a regional conference. The unique predefined methodology of this project that was strictly followed from conception to completion was essential to the project's success. Crucial tasks within this methodology include periodic pre-scheduled meetings between the students and municipal leaders, separate weekly advising sessions with the industry advsior and university advisor, and a presentation to the members of the community as their designs progressed to allow the community to voice their opinions and gain acceptance. Due to the many accomplishments and benefits that resulted from this collaborative student project, the methodology that paved the way to success can serve as a model to other institutions and government agencies interested in enhancing the undergraduate engineering technology student experience and benefiting underserved communities in need of assistance to safeguard their residents through infrastructure improvements.
\end{abstract}

\section{Introduction}

In the Spring 2016 academic semester, two Savannah State University (SSU) Civil Engineering Technology (CET) senior undergraduate students satisfied their 3-credit Senior Capstone Project course by producing a proposed site plan and architectural plans for a municipal building for the City of Midway, Georgia, with accompanied energy analyses and a budget analysis. Their project, entitled The Conceptual Design Plan for Midway, Georgia's Municipal Complex, was a collaborative effort between the students, their faculty capstone advisor, the EPA Region 4 
College/Underserved Community Partnership Program (CUPP), the Thriving Earth Exchange (TEX), and the City of Midway, Georgia. This collaboration is illustrated in Figure 1 below.

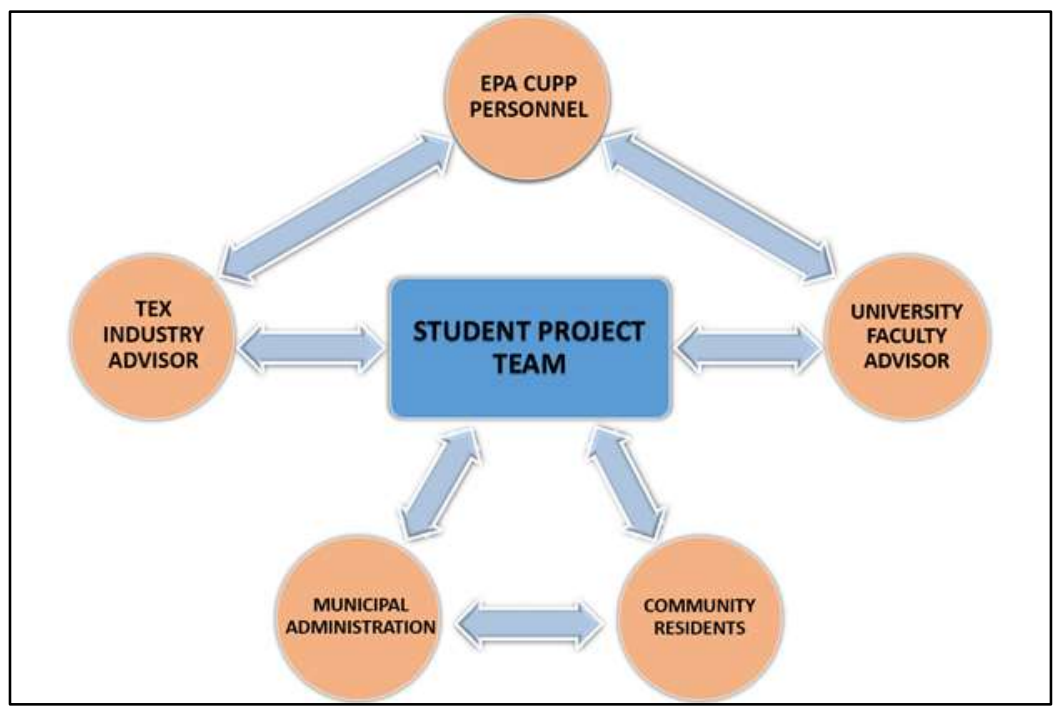

Figure 1: Communication in project collaboration

In addition, the project implemented sustainable engineering design features and materials, and was made available by CUPP.

According to the U.S. EPA:

The CUPP is based on developing partnerships between small, underserved communities and geographically close colleges/universities to provide a variety of technical support at no cost to those communities. This geographical proximity enables the colleges/universities to maximize the support provided by college students in their area of academic study while being overseen by professors supporting the effort. It is the intention of the CUPP to promote long term relationships between participating schools and communities which will create healthier and functionally improved communities [1]. The CUPP program was developed in 2011, solely within the U.S. EPA Region 4, and the first student projects within this initiative were completed in 2013. Students that participate with CUPP are invited to attend the two-day annual CUPP Conference in Atlanta, Georgia, and present their projects to the conference attendees. In 2016, there were over one hundred participants at the annual conference, including students and faculty from various universities/colleges, government agency representatives, and various community leaders. The conference is a venue for the students to receive recognition for their efforts, gain experience from presenting in a professional setting, and to gain knowledge from several informative sessions led by government agency researchers and officials. The community representatives are also provided with training sessions that focus on grant writing and loan procedures, as well as informative sessions for at-risk coastal communities on the identification and strategies regarding sea level rise vulnerabilities and emergency management [1].

Not all student projects that are supported by CUPP have obtained technical assistance from an external industry advisor provided by TEX, who assists the students with their expertise in one or more of the specific topics within their project scope. Upon identifying the lessons-learned from 
SSU's previous involvement in CUPP projects, this option has been determined to be extremely beneficial to the students' development and project success. TEX is a non-profit organization created by the American Geophysical Union (AGU), and a valuable resource for communities and scientists concerned with topics such as natural disasters, resource allocation, and climate change. TEX functions as a networking platform that addresses regional priorities by assisting with solving problems and initiating projects from the conceptual stage to the detailed engineering solution [2].

Prior to the Spring 2016 academic semester, SSU partnered with CUPP on two previous CET Senior Capstone student projects: (1) A Public Utility Map for the City of Riceboro, Georgia, and (2) Economic Impact Study: King's Bay Naval Base, Camden County, Georgia. Each of these projects satisfied the requirements of SSU's Senior Capstone Project course; however, these projects were performed during the early exploratory stages of the SSU/CUPP partnership and our joint methodology and process for project success were still being formulated. These three projects did provide the project collaborators with valuable lessons learned, and an understanding that there were key elements that these projects lacked:

- Members of the community should have a voice in the project scope and design features, as they will be the main users and beneficiaries of the infrastructure improvement or addition. Addressing this key element in the project process, which provides a forum for the residents of the community to express their opinions, may result in a heightened approval or acceptance of the project proposal. This claim is also supported by Dulaski (2013), "Local citizens are a critical part of the (engineering senior design) project success and must be included" [3].

- Having just one project advisor, the university faculty member, for assisting the students with the technical aspect of the project design, may not be the most efficient practice for providing the students with the technical assistance they may need. This realization is an understanding that certain aspects of the project scope may be outside of the faculty member's specialization; therefore, an external advisor with experience in the technical topic or industry would be beneficial to the accuracy and efficiency of the students' engineering design.

- The research and technical engineering work the students perform throughout the project duration should be available for all parties to view to allow for efficient and transparent project management. This key element of the project process can be addressed by creating a cloud-based data folder for uploading, viewing, and editing files. This file sharing method can enhance the project management effectiveness and the communication among the students, advisors, and community leaders, can be a means to pinpoint inaccuracies that may be present is the student's data collection, and provide a way for the advisors to crosscheck and verify the students' accuracy throughout their engineering design.

This was the first time the student project team members have been involved with a real-world project, and the complexity of the proposed project scope, in addition to the demands of a multiparty alliance, may seem overwhelming to students that lack previous experience with a project such as this. It was the predefined methodology and schedule of milestone dates, in conjunction with the collaborative advisement, that eased this burden on the students and allowed them to focus on each individual task, rather than overwhelming them with the complexity of reaching a 
final design solution. This collaborative advisement from the industry advisor and faculty advisor required efficient communication between the students and their advisors, with the industry advisor providing guidance on the sustainability features of their design, as well as verifying the current engineering and construction standards the students identified. Whereas the faculty advisor provided guidance on the site plan geometrics and public utilities, architectural floor plans, hydrological engineering calculations, design software, and projecting the cost estimate. Each student had their own role in the project and addressed these said topics, just as an actual design team of an engineering design firm commonly functions. Therefore, a group effort of this nature added to the collaboration and communication demands, and since the communication and data sharing strategies between the parties were established in the beginning stage of the project, the students were able to progress efficiently, avoid miscommunications and maintain their schedule.

The benefits of this collaborative project extend to all parties of the collaboration, specifically, the students, the faculty advisor, and the community that lacks the resources or funding for a particular need related to its infrastructure or general well-being of its residents. According to CUPP:

Communities benefit from the investment of innovative technical assistance and approaches provided by students attending nearby academic institutions. Students benefit by utilizing their learned curriculum to gain practical experience that can serve as a resume builder, while earning course credits through their academic institution. Federal agencies benefit from the interagency collaboration by seeing an improvement in the effective and efficient use of resources [1].

\section{Student benefits}

The students highlighted throughout this paper were seniors in the CET baccalaureate program at SSU that not only willingly participated in the CUPP initiative, but also satisfied their requirements for a 3-credit Senior Capstone course, which is a mandatory requirement of the program. Their involvement with this collaborative project allowed the students to gain experience with a practical, real-world engineering project and enabled them to use the skills introduced throughout their curriculum, as well as provide them with an opportunity to begin to refine their communication and project management skills. According to ABET (2017):

"Baccalaureate degree programs must provide a capstone or integrating experience that develops student competencies in applying both technical and non-technical skills in solving problems" [4]. Furthermore, Dulaski (2013), has stated that similar senior capstone project with municipal participation is common throughout programs in the United States, and in some cases, the senior capstone course requires municipal partnerships; however, “...the depth and breadth of community participation is often unknown" [3].

At the conclusion of the CUPP/Senior Capstone project entitled The Conceptual Design Plan for Midway, Georgia's Municipal Complex, the specific benefits the students gained from their experience include:

- An added awareness of environmental stewardship and sustainable engineering practices and materials 
- An opportunity to enhance their résumé, from both highlighting their successful project and their presentation at the annual CUPP Conference

- Experience with a real-world project that improved their project management, budgeting, and scheduling skills with engineering-related projects

- Exposure at a professional conference, allowing them to network and interact with industry professionals

- Improving their personal communication and time management skills, as well as providing them with an added understanding of the importance of communicating with various parties throughout managing a project

- Allowing the students to feel the satisfaction of assisting a community in need and to directly see their impact on the residents of the community

\section{Faculty benefits}

The primary focus of the CUPP/Senior Capstone project was on student development and providing assistance to an underserved community; however, the university faculty advisor also benefitted from the successful collaborative student project in several ways:

- An opportunity to strengthen business relationships with the regional industry professionals provided by TEX, as well as the municipal government leaders

- An opportunity to showcase the successful project among colleagues, present the project at industry conferences, or publish the impacts of the project

- Allow the faculty to further enhance their own technical industry skills

- By witnessing the development of the students throughout the project, the faculty advisor may have a feeling of satisfaction that they were able to assist the students to transition from students to industry professionals.

- Similar to a benefit of the students, the faculty advisor may also feel the satisfaction of assisting a community in need and improving the lives of its residents.

\section{Community benefits}

Even though the term 'underserved community' relates to healthcare availability in many research applications, this term is used by CUPP in relation to a community's lack of resources and the need for infrastructure necessary for maintaining safety and preserving the well-being of its residents. Studies have shown that Americans living in poverty have a higher likelihood for poor health. Furthermore, additional characteristics of underserved populations include the economically disadvantaged, racial and ethnic minorities, and locations with a high number of elderly or homeless citizens [6]. Since the proposed design in this project has yet to progress into construction phase, the potential benefits to the community include:

- With a more efficient multi-purpose municipal complex, which includes a community gathering place and sustainability features within the proposed site plan, the City of Midway may have an increased potential to accommodate future population growth.

- With weather-resilient design practices, the complex can provide shelter to residents during natural disaster events.

- The quality of life for the residents may be enhanced by allowing the potential funds for the municipal complex design to be spent on other needs of the community. 
- The participation of the citizens in the design process adds to the sense of community between its residents and municipal leaders.

- Through the sustainability environmentally-conscious features of the proposed building and site plan, the environmental awareness of the community can be heightened.

- The City of Midway, GA was able to have a preliminary design of their new municipal complex at no cost to the city and taxpayers.

\section{Project Methodology}

The following steps were used in successfully completing the collaborative project, which have been refined from the lessons-learned of previous SSU/CUPP Senior Capstone projects. These steps may be replicated by various civil engineering or civil engineering technology programs that are interested in becoming involved with the CUPP initiative.

\section{Step 1: Student team and faculty advisor meet at start of semester}

At this first initial meeting, the students and university faculty advisor agree upon a single CUPP project from an available list provided by CUPP. The Senior Capstone course guidelines are also listed and described by the faculty advisor. In addition, a weekly meeting time is determined, where the students and faculty advisor discuss the weekly tasks and to ensure that the project is progressing as planned and the roles of each student member is determined (ex. team leader, CAD designer, etc.).

\section{Step 2: Student team selects TEX industry advisor}

Together, the students and faculty advisor contact TEX, and the scope of the project is described to the TEX staff. TEX will then report back to the project team leader (generally within a few days) and provide the contact information of regional industry professionals that may be interested in providing technical assistance throughout the duration of the project. After the team leader reached out to the available industry professionals, the project's TEX advisor is then finalized.

Step 3: Students, faculty advisor, TEX industry advisor, CUPP personnel, and municipal leaders meet

At this meeting, the scope of the project is defined in detail, the contact information is exchanged between all parties, an online cloud-based file sharing folder is shared with all parties for document sharing and collaboration, any additional needs within the project are identified, student project funding is discussed (ex. student transportation costs), and the technical needs are identified (ex. field testing equipment access, software, etc.). In addition, all parties perform a site walkthrough of the proposed location of the project, where photos are taken and information is gathered and recorded by the students.

Step 4: First weekly meeting between student team and faculty advisor

During this meeting, the abstract of the student project is due and the plan of action is determined by the students and faculty advisor, which allows the project milestones to also be determined for scheduling purposes. 
Step 5: Second weekly meeting between student team and faculty advisor

At this meeting, the bound project proposal is due, which include the following topics (not limited to):

- Design objectives

- Technical approach

- Proposed sustainability features

- Identify customer needs

- Identify local/state/federal engineering and construction specifications

- Project management structure

- Budget

- Gantt Chart of project schedule

- Résumés of team members

Step 6: Project implementation- preliminary design stage

This phase of the project accounts for the bulk of the time required for the project completion and requires weekly meetings between the students and their faculty advisor, weekly communication between the students and their TEX industry advisor, any necessary field testing, preliminary student designs, student research of local, state, and federal regulations/engineering specifications, research of relevant sustainable design and materials, and any other work necessary.

Step 7: Students present preliminary design to municipal leaders and community members At this step, the students should have completed the majority of their preliminary design or multiple alternative designs. This is a very critical step to promote acceptance of the proposed project to the residents, where the students present their progress with their design proposals to the municipal leaders and the community. It is at this presentation that the members of the community become aware of the project and can voice their opinions and concerns. Following their presentation, the student and municipal leaders meet in private to make additions or changes to their proposed designs.

Step 8: Refine design stage

During this stage of the project, the students modify their designs based on the suggestions of the stakeholders. Their design is finalized using the relevant software (CAD), a cost estimate is performed, a sustainability/environmental impact or Life Cycle Cost Analysis (LCCA) is performed, and the final project report (which is a modification of their original project proposal) and presentation are developed.

Step 9: Present project at university senior capstone fair

The completed design is presented by the students at their university Senior Capstone Fair. If this event is not applicable, a presentation is announced where other university faculty and students are invited to attend. This event allows the students to present their project and efforts in a professional setting.

Step 10: Present project at annual CUPP Conference

Here, the students are provided with an opportunity to receive recognition for their time and effort and to showcase their project in a professional setting, among industry leaders and 
professionals. This opportunity also allows the students to add an accomplishment to their résumés. It is also at this conference that the community leaders can discuss future funding opportunities with CUPP personnel to see their project into fruition.

\section{Results}

The collaborative Senior Capstone project was successfully completed within the Savannah State University's Senior Capstone Project course timeline, and was within the City of Midway, Georgia's proposal time frame. Since the City of Midway was operating from a rented facility, a new complex was the only option they sought to explore; therefore, the students presented multiple proposed floor plans of the complex for the community and city administrators to evaluate. These alternative solutions are shown in Figures 2 and 3, with Proposed floor plan \#2 (Figure 3 ) being the layout favored by the community and selected by the community leaders. Additional photos of the project design are shown in Figures 4 and 5.

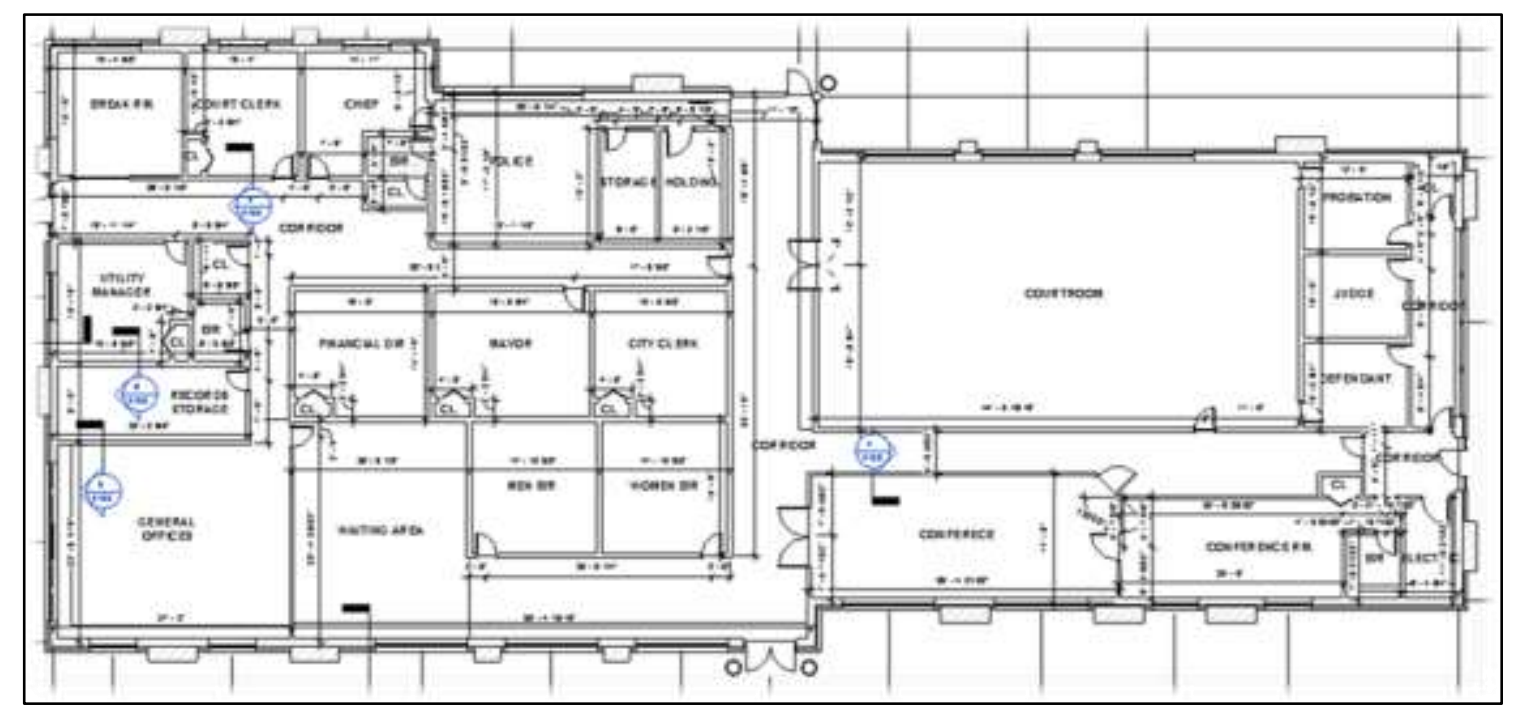

Figure 2: Proposed floor plan \#1 [5]

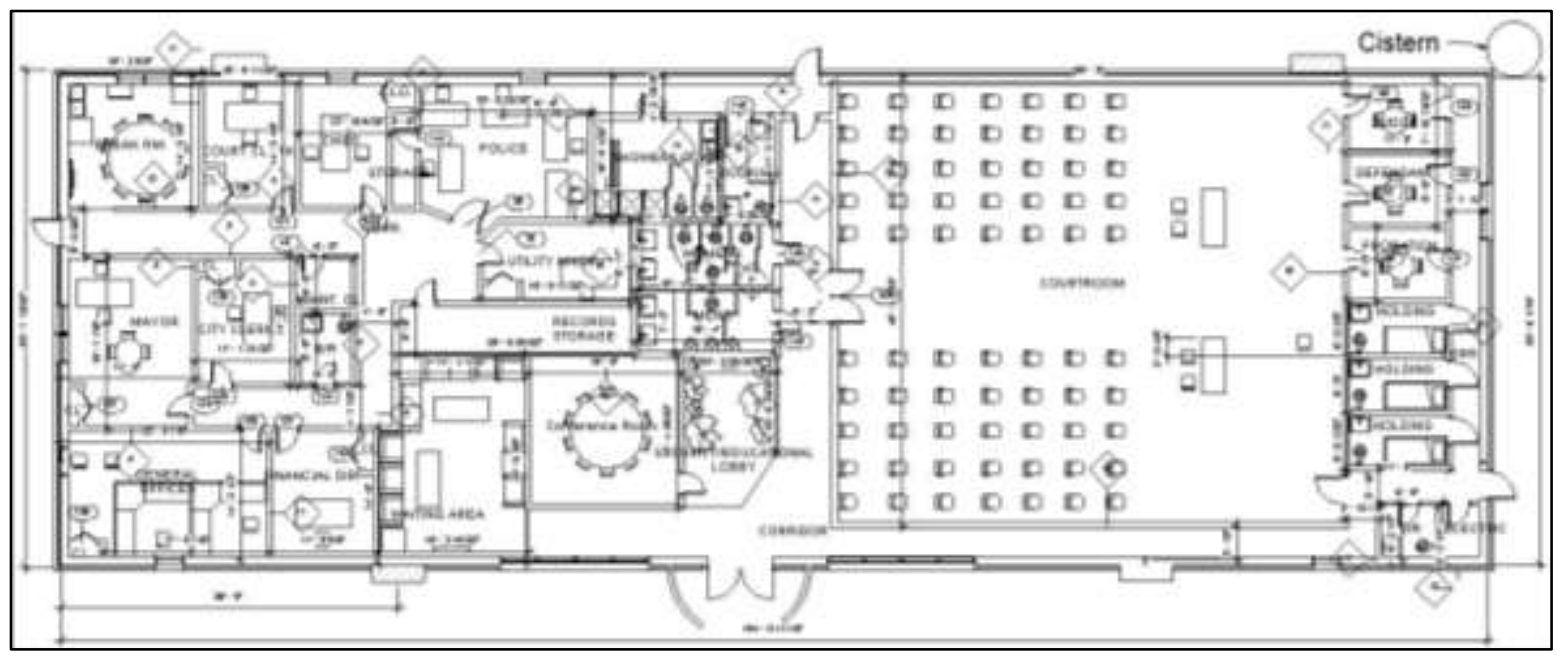

Figure 3: Proposed floor plan \#2 [5] 


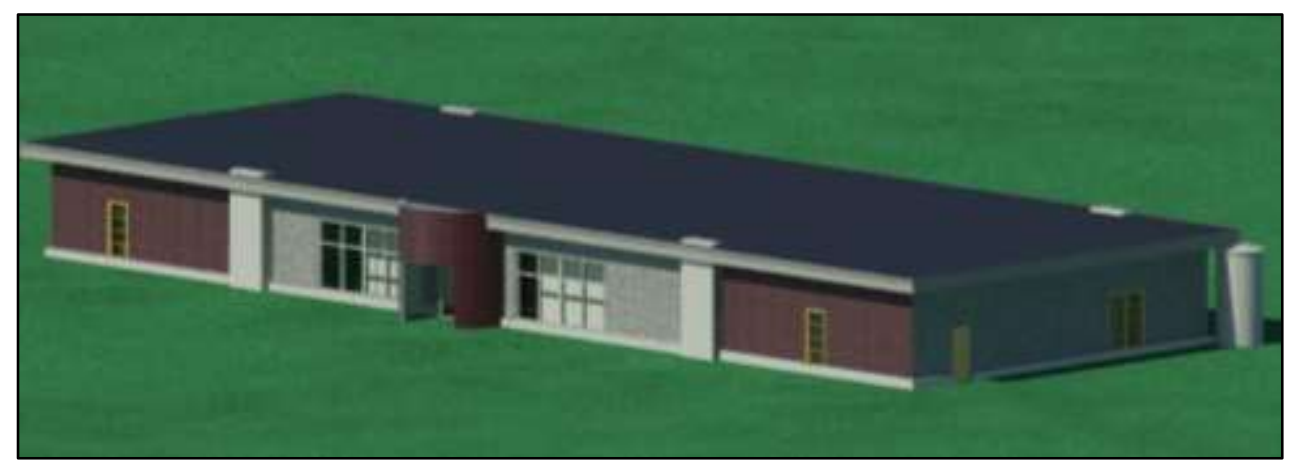

Figure 4: Architectural rendering [5]

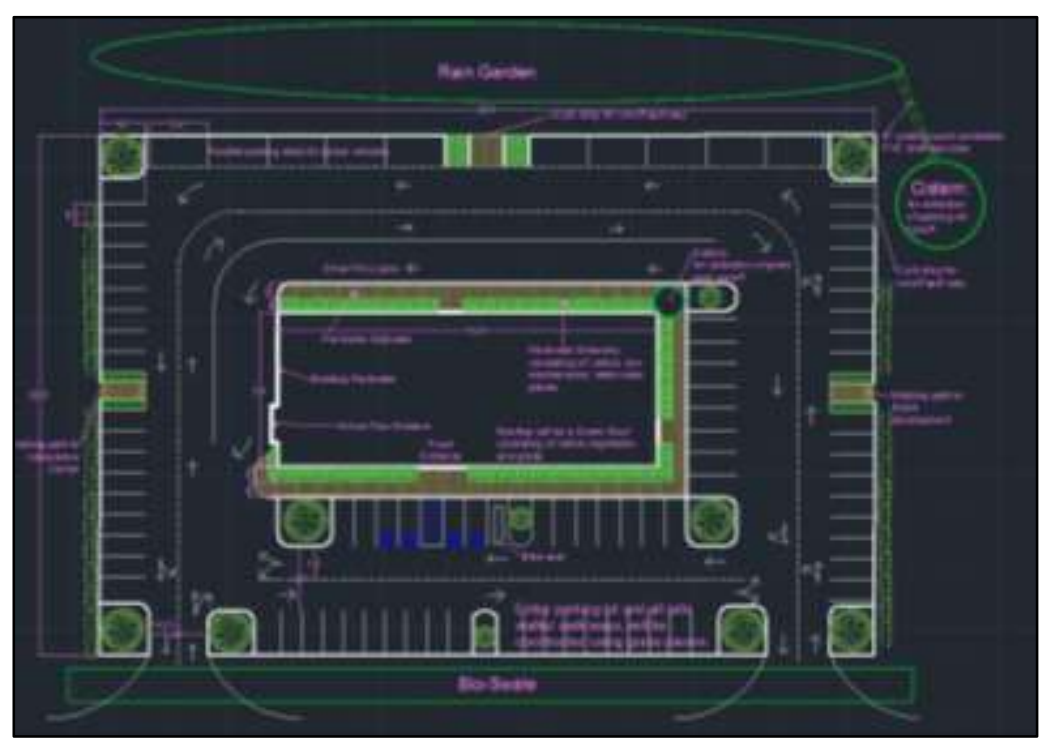

Figure 5: Proposed site plan [5]

Upon completion of the project process detailed within this paper, the project received accolades and exposure on a national level:

- $\quad$ The students presented their project the Administrator of the U.S. EPA at the 2016 Annual EPA CUPP Conference. Their project was also highlighted as the premier student success project, among several other university CUPP projects, and received the longest time slot to present.

- Based on the exceptional quality of the student engineering design, a regional engineering firm provided pro bono services to the City of Midway, Georgia, and after minor revisions, the firm stamped the engineering plans in order to move forward to the construction stage of the municipal complex.

- TEX has publicized the student project on their website.

- TEX has provided a detailed description of the student project under their website's 'Success Stories'. This project description highlights the project's positive impact on the community of Midway, Georgia, and describes the student experience and lessons learned, the project design process, and the sustainability features incorporated into the design [7]. 
- The project was showcased by TEX at the 2016 Annual American Geophysical Union (AGU) Meeting.

In addition to the aforementioned Senior Capstone project accolades, the Mayor of Midway, Georgia, Dr. Clemontine F. Washington, had high praises of the project's outcomes: "The students' CUPP project was excellent; it was one that was surely needed for our community. It served as a springboard for getting the city to move forward with building a new city hall. When approached by the EPA to participate in CUPP, it sounded like a great idea, and the end result benefitted the city, the university, and the students on many levels".

\section{References}

[1] United States Environmental Protection Agency, "College/Underserved Community Partnership Program (CUPP)," 13 May 2016. [Online]. Available: https://www.epa.gov/communityhealth/collegeunderserved-community-partnershipprogram-cupp. [Accessed 15 January 2017].

[2] Thriving Earth Exchange, "About Thriving Earth Exchange," 2017. [Online]. Available: http://thrivingearthexchange.org/about-tex/. [Accessed 15 January 2017].

[3] D. M. Dulaski, "Improving Students' Capstone Experience with Community Participation," in 2013 ASEE Annual Conference \& Exposition, Atlanta, Georgia, 2013.

[4] ABET Engineering Technology Accredidation Commission, "Criteria for Accrediting Engineering Technology Programs," ABET, Baltimore, MD, 2016.

[5] M. McKay and U. Virgo, "The Conceptual Design Plan for Midway, Georgia's Municipal Complex," B.S. capstone, Savannah State University, Savannah, GA, 2016.

[6] "Vulnerable Populations: Who Are They?," The American Journal of Managed Care, vol. 12, no. 13, SUP, pp. S348-352, 2006.

[7] N. Lamontagne, "Collaborative Building Design Brings Together Engineering Students and Local Community," Thriving Earth Exchange, 2017. [Online]. Available: http://thrivingearthexchange.org/tex-stories/collaborative-building-design-brings-togetherengineering-students-and-local-community/. [Accessed 18 March 2017]. 